\title{
Downregulation of the Canonical WNT Signaling Pathway by TGF $\beta 1$ Inhibits Photoreceptor Differentiation of Adult Human Müller Glia with Stem Cell Characteristics
}

\author{
Angshumonik Angbohang, ${ }^{1,{ }^{*}} \mathrm{Na} \mathrm{Wu},{ }^{1,2,{ }^{*}}$ Thalis Charalambous, ${ }^{1}$ Karen Eastlake, ${ }^{1}$ Yuan Lei, ${ }^{2}$ \\ Yung Su Kim, ${ }^{1}$ Xinghuai H. Sun, ${ }^{2}$ and G. Astrid Limb ${ }^{3}$
}

Müller glia are responsible for the retina regeneration observed in zebrafish. Although the human retina harbors Müller glia with stem cell characteristics, there is no evidence that they regenerate the retina after disease or injury. Transforming growth factor- $\beta$ (TGF $\beta$ ) and Wnt signaling regulate retinal neurogenesis and inflammation, but their roles in the neural differentiation of human Müller stem cells (hMSC) are not known. We examined hMSC lines in vitro for the expression of various Wnt signaling components and for their modulation by TGF $\beta 1$, as well as the effect of this cytokine on the photoreceptor differentiation of these cells. Culture of hMSC with a combination of factors that induce photoreceptor differentiation of hMSC (FGF2, taurine, retinoic acid, and insulin-like growth factor type1; FTRI), markedly upregulated the expression of components of the canonical Wnt signaling pathway, including WNT2B, DKK1, and active $\beta$-CATENIN. Although FTRI did not modify mRNA expression of $W N T 5 B$, a component of the noncanonical/planar cell polarity Wnt pathway, it upregulated its secretion. Furthermore, TGF $\beta 1$ not only decreased $W N T 2 B$ expression, but also inhibited FTRI-induced photoreceptor differentiation of hMSC, as determined by expression of the photoreceptor markers NR2E3, RHODOPSIN, and RECOVERIN. Inhibition of TGF $\beta 1$ signaling by an ALK5 inhibitor prevented TGF $\beta 1$-induced changes in the expression of the two Wnt ligands examined. More importantly, inhibition of the canonical WNT signaling by XAV-939 prevented FTRI-induced photoreceptor differentiation. These observations suggest that TGF $\beta$ may play a key role in preventing neural differentiation of hMSC and may constitute a potential target for induction of endogenous regeneration of the human retina.

\section{Introduction}

$\mathrm{T}$ HE SPONTANEOUS RETINAL regeneration observed in zebrafish has been ascribed to the ability of a population of Müller glia to dedifferentiate and become progenitors that give rise to retinal neurons [1]. Although Müller glia dedifferentiation into retinal progenitors has not been demonstrated in vivo in the human eye, a population of Müller glia able to proliferate indefinitely in vitro has been identified [2]. Unlike their inability to regenerate the human retina, when cultured with selective growth and differentiation factors these cells can be induced to acquire characteristics of retinal neurons, for which they have been termed human Müller stem cells (hMSC) [2-5]. The reasons why Müller glia do not regenerate the adult human retina are not known, but it is possible that factors produced in adult life or during degenerative diseases may prevent these cells from exerting these functions in vivo. Most retinal degenerative conditions that lead to blindness, including inflammatory, proangiogenic, and dystrophic retinal diseases, have been associated with abnormal proliferation of Müller glia that does not lead to repair, but to the formation of glial scarring [6]. Many of these conditions are also accompanied by local increased production of proinflammatory cytokines, such as transforming growth factor- $\beta$ (TGF $\beta$ ) [7-9], which may potentially modify the neural progenicity of hMSC.

TGF $\beta$ signaling mediated through Smad 2/3, which is controlled by transcriptional corepressors such as Tgif1 and Six $3 b$, has been demonstrated to regulate Müller glia-derived photoreceptor regeneration in the adult zebrafish [10]. In addition, signaling by the TGF $\beta$ superfamily (including TGF $\beta 1$, TGF $\beta 2$, TGF $\beta 3$, and bone morphogenic proteins) regulates mammalian cell proliferation, differentiation, migration, and apoptosis during embryogenesis [11]. During early development, TGF $\beta$ has been shown to synergize or antagonize with Wnt proteins, a family of highly conserved

\footnotetext{
${ }^{1}$ Division of Ocular Biology and Therapeutics, UCL Institute of Ophthalmology, London, United Kingdom.

${ }^{2}$ Department of Ophthalmology and Visual Science, Eye \& ENT Hospital, Shanghai Medical College, Fudan University, Shanghai, China.

${ }^{3}$ NIHR Biomedical Research Centre for Ophthalmology at Moorfields Eye Hospital and UCL Institute of Ophthalmology, London, United Kingdom.

*These authors contributed equally to the work.

(C) Angshumonik Angbohang, et al., 2015; Published by Mary Ann Liebert, Inc. This Open Access article is distributed under the terms of the Creative Commons License (http://creativecommons.org/licenses/by/4.0), which permits unrestricted use, distribution, and reproduction in any medium, provided the original work is properly credited.
} 
secreted signaling molecules that regulate cell-to-cell interactions [12-14]. Wnt signaling is a major regulator of neurogenesis in the adult hippocampus [15], and it has been suggested that the pathways initiated by various Wnt ligands may depend on the receptors expressed by a given target cell [16]. Activation of the canonical Wnt signaling by TGF $\beta$ has been shown to mediate fibrosis [17], and cooperation between TGF $\beta$ and Wnt signaling pathways are known to play a role in controlling developmental events such as the regulation of osteoblast differentiation of human mesenchymal stem cells [18]. In addition, it has been shown that Wnt signaling is activated during retina degeneration and that Wnt activation protects retinal cells from oxidative stress. From these observations it is suggested that Wnt activation by growth factors may increase the threshold for apoptosis and prevent further photoreceptor degeneration [19].

Although interaction of these signaling pathways in fish and amphibians as well as small mammals during development and adult regeneration are documented [20], there is no knowledge of the role of these factors in the regulation of neural differentiation of hMSC in the adult human eye. On this basis, we investigated the role of TGF $\beta 1$ on the regulation of the WNT signaling pathway in hMSC by examining the effect of this cytokine on the expression of the DKK1 and WNT2B and WNT5B ligands, previously shown to be expressed by mammalian Müller glial cells [19], as well as on the phosphorylation of $\beta$-catenin in cells undergoing photoreceptor differentiation. In this study, we demonstrate that TGF $\beta 1$ downregulates the expression of the canonical Wnt signaling ligand WNT2B and increases the phosphorylation of $\beta$-catenin, while upregulating the expression of the noncanonical Wnt ligand WNT5B in hMSC. Interestingly, TGF $\beta 1$ inhibits photoreceptor differentiation of hMSC in vitro, an event shown to be mediated by activation of the canonical Wnt signaling pathway.

\section{Materials and Methods}

\section{Human Müller stem cell culture}

Human Müller stem cell lines (hMSC) developed in our laboratory were cultured as previously described [2]. Briefly, cells were grown in Dulbecco's modified Eagle's medium (DMEM) (Gibco-BRL) containing $10 \%$ fetal calf serum (FCS) and $1 \%$ Penicillin/Streptomycin mix. Three different hMSC, named MIO-M1, MIO-M7, and MIO-M8, from passages 7 to 33 were used for the experiments. To assess the

Table 1. Primer Sequences Used for RT-PCR to Assess Gene Expression of Components of the Wht Signaling Pathway and Photoreceptor Differentiation Markers in hMSC

\begin{tabular}{|c|c|c|c|c|}
\hline Gene & Accession No. & Sequence & $\operatorname{Tm}\left({ }^{\circ} \mathrm{C}\right)$ & Product size(bp) \\
\hline$\beta$-ACTIN & NM_001101 & $\begin{array}{l}\text { (F) CATGTACGTTGCTATCCAGGC } \\
\text { (R) CTCCTTAATGTCACGCACGAT }\end{array}$ & 60 & 250 \\
\hline$W N T 2 B$ & NM_004185.3 & $\begin{array}{l}\text { (F) GACGGCAGTACCTGGCATAC } \\
\text { (R) CTCCTTAATGTCACGCACGAT }\end{array}$ & 58 & 188 \\
\hline WNT3A & NM_033131.3 & $\begin{array}{l}\text { (F) AGATGGTGGTGGAGAAGCAC } \\
\text { (R) GTAGCAGCACCAGTGGAACA }\end{array}$ & 58 & 290 \\
\hline WNT5B & NM_032642.2 & $\begin{array}{l}\text { (F) TTCTGACAGACGCCAACTC } \\
\text { (R) TGACTCTCCCAAAGACAGATG }\end{array}$ & 58 & 264 \\
\hline WNTSB & NM_003393.3 & $\begin{array}{l}\text { (F) CCATGAACCTGCACAACAA } \\
\text { (R) TGAGTGCTGCGTGGTACTTC }\end{array}$ & 58 & 174 \\
\hline WNT11 & NM_004626.2 & $\begin{array}{l}\text { (F) TGACCTCAAGACCCGATACC } \\
\text { (R) GCTTCCGTTGGATGTCTTGT }\end{array}$ & 58 & 214 \\
\hline FZD1 & NM_003505.1 & $\begin{array}{l}\text { (F) AGACCGAGTGGTGTGTAATGA } \\
\text { (R) ATACTGTGAGTTGGCTTCGAT }\end{array}$ & 60 & 253 \\
\hline FZD4 & NM_012193 & $\begin{array}{l}\text { (F) AACTTTCACACCGCTCATC } \\
\text { (R) CAGCATCATAGCCACACTTG }\end{array}$ & 55 & 391 \\
\hline FZD5 & NM_003468.3 & $\begin{array}{l}\text { (F) TTCTGGATAGGCCTGTGGTC } \\
\text { (R) CGTAGTGGATGTGGTTGTGC }\end{array}$ & 60 & 214 \\
\hline FZD7 & NM_003507 & $\begin{array}{l}\text { (F) GCTCTTTACCGTTCTCACCTA } \\
\text { (R) CAGGATAGTGATGGTCTTGAC }\end{array}$ & 55 & 388 \\
\hline$\beta$-CATENIN & NM_001904.3 & $\begin{array}{l}\text { (F) TACCTCCCAAGTCCTGTATGAG } \\
\text { (R) TGAGCAGCATCAAACTGTGTAG }\end{array}$ & 60 & 180 \\
\hline$D K K 1$ & NM_012242.2 & $\begin{array}{l}\text { (F) CCTTGAACTCGGTTCTCAATTCC } \\
\text { (R) CAATGGTCTGGTACTTATTCCCG }\end{array}$ & 60 & 138 \\
\hline RHODOPSIN & NM_000539 & $\begin{array}{l}\text { (F) GCTTCCCCATCAACTTCCTCA } \\
\text { (R) AGTATCCATGCAGAGAGGTGTAG }\end{array}$ & 60 & 156 \\
\hline$N R 2 E 3$ & NM_014249.3 & $\begin{array}{l}\text { (F) GGCGTGGAGTGAACTCTTTC } \\
\text { (R) CTGGCTTGAAGAGGACCAAG }\end{array}$ & 58 & 230 \\
\hline RECOVERIN & NM_002903 & $\begin{array}{l}\text { (F) AGCTCCTTCCAGACGATGAA } \\
\text { (R) CAAACTGGATCAGTCGCAGA }\end{array}$ & 60 & 150 \\
\hline
\end{tabular}

hMSC, human Müller stem cells; RT-PCR, reverse transcription-polymerase chain reaction. 
effect of TGF $\beta 1$, cells were cultured for 7 days in the presence or absence of human recombinant TGF $\beta 1$ (PeproTech) at $\log _{10}$ concentrations ranging from 0.1 to $100 \mathrm{ng} / \mathrm{mL}$. To investigate the effect of TGF $\beta 1$ on the neural differentiation of hMSC, cells were cultured for 7 days in flasks coated with basement membrane protein (bMP) (Sigma-Aldrich) in the presence or absence of TGF $\beta 1(50 \mathrm{ng} / \mathrm{mL})$ and factors known to induce the expression of photoreceptor cell markers as previously published by our group [3]. Briefly, to induce photoreceptor differentiation, cells were cultured for 5-6 days in bMP-coated flasks in the presence of $20 \mathrm{ng} / \mathrm{mL}$ FGF2, $20 \mu \mathrm{M}$ taurine (Sigma Aldrich), $5 \mu \mathrm{M}$ retinoic acid (Sigma Aldrich), and $100 \mathrm{ng} / \mathrm{mL}$ IGF-1 (PeproTech) (FTRI) [3]. In selected experiments, hMSC were stimulated with recombinant human TGF $\beta 1$ (PeproTech) alone, or in combination with inhibitors of the TGF $\beta$ pathway or $\beta$-catenin at the following concentrations of $10 \mu \mathrm{M}$ TGF $\beta$ type I (ALK5) receptor inhibitor SB431542 (Selleckchem), $20 \mu \mathrm{M}$ JNK inhibitor SP600125 (Sigma-Aldrich), and $10 \mathrm{nM} \beta$-CATENIN inhibitor XAV-939 (Selleckchem). Furthermore, to investigate the effect of WNT2B and WNT5B on the expression of DKK1, hMSC were cultured with these recombinant proteins for 7 days at concentrations of $100 \mathrm{ng} / \mathrm{mL}$ (WNT2B; Abnova) and $500 \mathrm{ng} / \mathrm{mL}$ (WNT5B; R\&D Systems).

\section{RNA isolation and reverse transcription- polymerase chain reaction}

Total RNA was isolated using the RNeasy Mini Plus Kit (Qiagen) according to the manufacturer's instructions. Quantification of total RNA was performed using a NanoDrop spectrophotometer (Thermo Scientific). Reverse transcription (RT) was performed using $1 \mu \mathrm{g}$ RNA as per the manufacturer's instructions (Life technologies). Polymerase chain reaction (PCR) was then performed using the primer sequences shown in Table 1 . Amplification was performed in a $20 \mu \mathrm{L}$ volume by

A
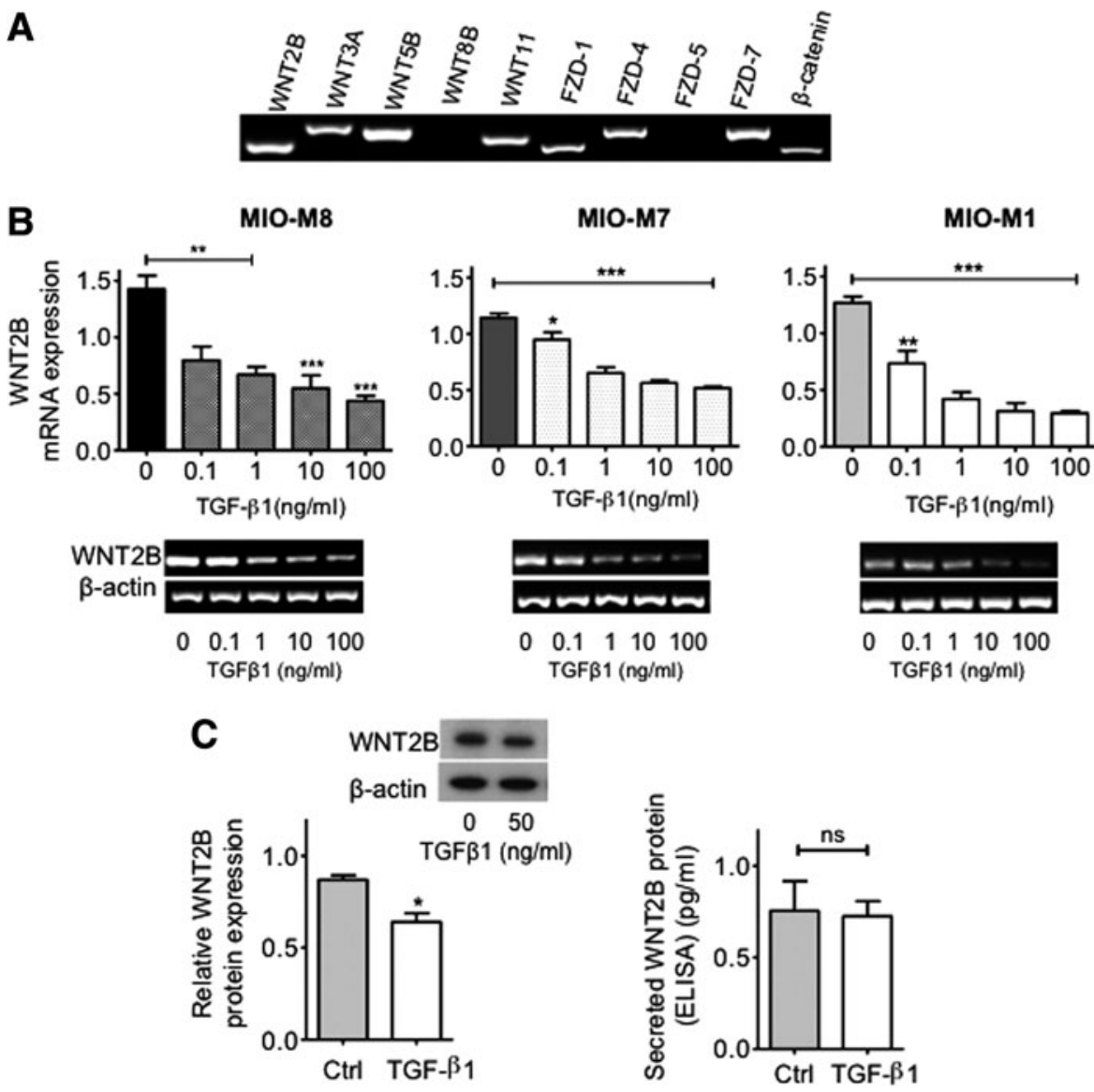

FIG. 1. Expression of mRNA coding for molecules of the Wnt signaling pathway in human Müller stem cells (hMSC) and modulation of $W N T 2 B$ expression by transforming growth factor- $\beta$ (TGF $\beta 1$ ). (A) hMSC express mRNA coding for various components of the canonical and noncanonical Wnt signaling pathway. (B) TGF $\beta 1$ downregulation of the expression of mRNA coding for $W N T 2 B$ occurred in a dose-response manner in three different hMSC lines (MIO-M8, MIO-M7, and MIO-M1) after 7 days culture with concentrations of this cytokine ranging between 0.1 and $100 \mathrm{ng} / \mathrm{mL}$. Histograms represent the mean \pm standard error of the mean (SEM) from UV spectrophotometer readings of gel bands. Representative bands are shown below the histograms; $n=3-4$. ANOVA test, $* P<0.05$; ** $P<0.01$; *** $P<0.001$. (C) A significant decrease in the expression of WNT2B protein was observed by western blot analysis of lysates from cells cultured with $50 \mathrm{ng} / \mathrm{mL}$ of TGF $\beta 1$. Histograms represent the mean \pm SEM of the relative optical density readings of gel bands. Representative bands are shown above the histograms; $n=3$. Student's $t$-test; $* P<0.05$. Minimally detectable levels of secreted WNT2B examined by Enzyme-Linked Immunosorbent Assay (ELISA) methods were observed in supernatants of cells cultured in the presence or absence of TGF $\beta 1$, and no differences between the two conditions were observed; $n=3$. Student's $t$-test; ns, not significant. 
mixing $10 \mu \mathrm{L}$ of $2 \times$ Green GoTaq Mix (Promega), $1 \mu \mathrm{L}$ of $10 \mu \mathrm{M}$ primers, and $0.5-1 \mu \mathrm{L}$ cDNA. Final volume was adjusted with RNAse-free water (Promega). The instrumental settings were as follows: initial denaturation step of $2 \mathrm{~min}$ at $95^{\circ} \mathrm{C}$, followed by $26-34$ cycles as follows: denaturation $94^{\circ} \mathrm{C}$ for $30 \mathrm{~s}$, annealing temperature for $30 \mathrm{~s}$ and extension $72^{\circ} \mathrm{C}$ for $30 \mathrm{~s}$, and one cycle of $72^{\circ} \mathrm{C}$ for $5 \mathrm{~min}$. PCR products were then analyzed by agarose gel electrophoresis (2\%) containing $10,000 \times$ GelRed Nucleic Acid Stain (Biotium).

\section{Protein analysis}

Western blotting. Cell lysates were prepared using RIPA buffer (Thermo Scientific) containing protease inhibitor cocktail (Sigma). Gels and buffer systems (NuPAGE; Invitrogen) were used for western blot analysis, as previously described [4,21] Briefly, $24 \mu \mathrm{L}$ of loading sample were prepared with $10 \mu \mathrm{g}$ protein, $2.4 \mu \mathrm{L}$ reducing agent $(10 \times), 6 \mu \mathrm{L}$ loading buffer (LDS $4 \times$ ), and water. Proteins were denatured at $80^{\circ} \mathrm{C}$ for $10 \mathrm{~min}$ before loading onto $4 \%-12 \%$ Bis-Tris gels. Gels were run using the MOPS buffer containing antioxidant at $180 \mathrm{~V}$ for $60 \mathrm{~min}$, after which they were semi-dry transferred onto polyvinylidene difluoride membranes (Millipore) at $10 \mathrm{~V}$ for $46 \mathrm{~min}$. Membranes were blocked in TBS $+0.1 \%$ Tween-20 containing 5\% skimmed milk and 5\% fetal bovine serum at room temperature for $1 \mathrm{~h}$. Primary antibodies, including rabbit anti-WNT2B (1:1,000; Abcam), rabbit anti-phosphorylated
$\beta$-CATENIN (1:1,000; Millipore), rabbit anti $\beta$-CATENIN (1:1,000; Abcam), anti-WNT5B (1:1,000; Abcam), and mouse monoclonal anti- $\beta$-ACTIN (1:5,000; Sigma), were diluted in blocking buffer for addition to the membranes, which were then incubated at $4^{\circ} \mathrm{C}$ overnight. Following $4 \times 20 \mathrm{~min}$ washes, membranes were incubated with a secondary antibody conjugated to horseradish peroxidase $(1: 10,000$; Jackson Laboratories, www.jacksonimmuno.com/) for $1 \mathrm{~h}$ at room temperature. The blots were visualized using the enhanced chemiluminescence advanced detection reagent ECL2 (Thermo Scientific) and a Fujifilm Imager (LAS-100; Fujifilm).

\section{Enzyme-Linked Immunosorbent Assay}

The hMSC were grown for 5-6 days in DMEM with 2\% FCS on bMP-coated flasks in the presence or absence of either human recombinant TGF $\beta 1(50 \mathrm{ng} / \mathrm{mL})$ or FTRI to induce photoreceptor differentiation as indicated above [3]. Supernatants were collected and used for Enzyme-Linked Immunosorbent Assay (ELISA) analysis for quantification of secreted DKK1 (R\&D Systems), WNT2B, and WNT5B (CUSABIO) using the manufacturer's instructions.

\section{Immunocytochemistry}

The hMSC were grown for 7 days in DMEM supplemented with $2 \%$ FCS on bMP-coated glass coverslips placed in 24-well
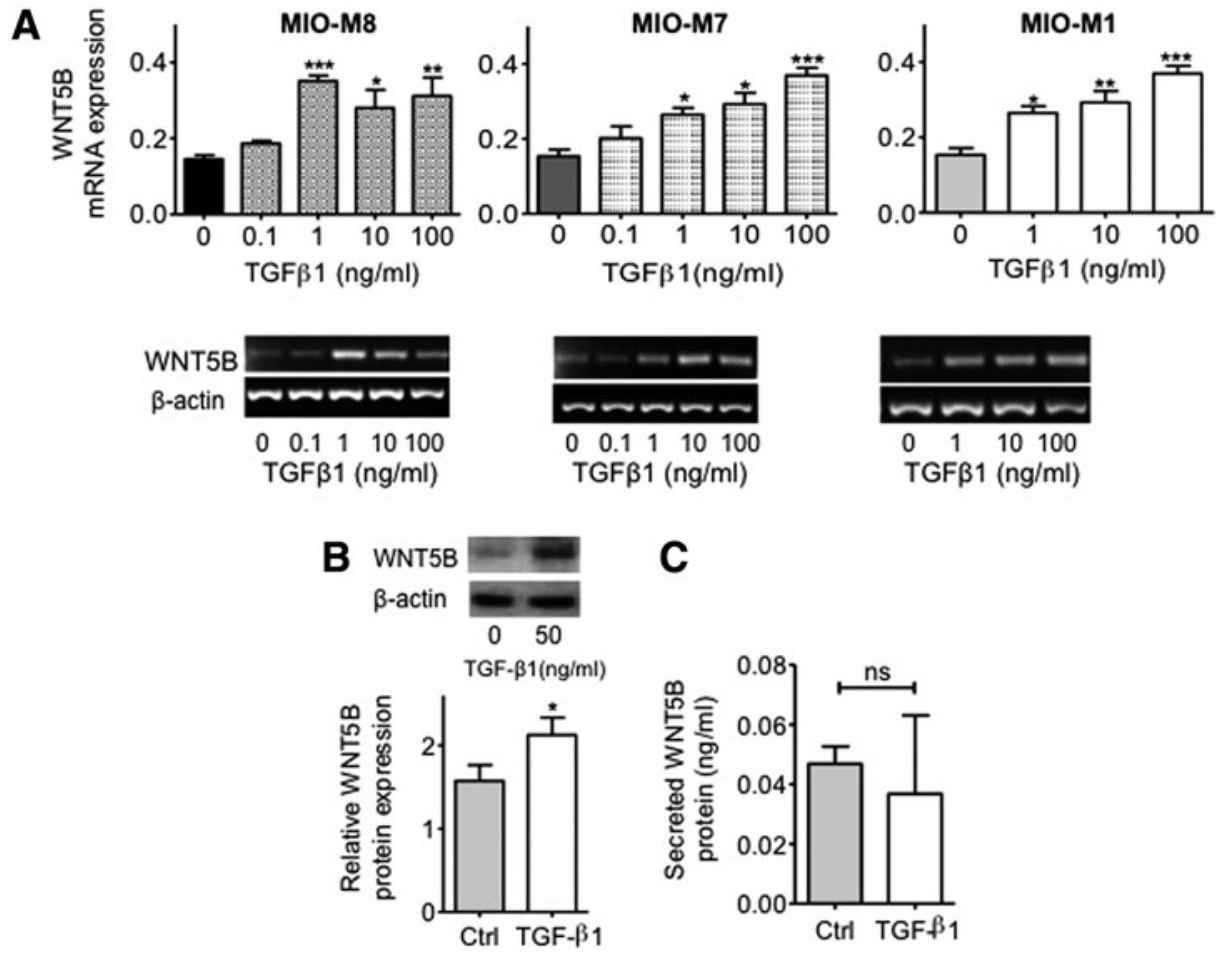

C

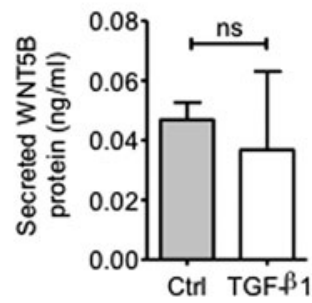

FIG. 2. TGF $\beta 1$ modulation on the expression of WNT5B in hMSC. (A) TGF $\beta 1$-induced upregulation of the expression of mRNA coding for WNT5B occurred in a dose-response manner in three different hMSC lines examined (MIO-M7, MIOM8, and MIO-M1). Histograms represent the mean \pm SEM from UV spectrophotometer readings of gel bands. Representative bands are shown below the histograms; $n=4$. ANOVA test, $* P<0.05 ; * * P<0.01 ; * * * P<0.001$. (B) Western blot analysis of cell lysates from hMSC showed a marked increase of intracellular protein in cells treated with TGF $\beta 1$ at a concentration of $50 \mathrm{ng} / \mathrm{mL}$ as compared with control cells. Histograms represent the mean \pm SEM of the relative optical density readings of gel bands. Representative bands are shown above the histograms; $n=4$. Student's $t$-test, $* P<0.05$. (C) Minimally detectable levels of secreted WNT5B, as examined by ELISA, were observed in supernatants of cells cultured in the presence or absence of TGF $\beta 1$, and no differences between the two conditions were observed; $n=3$. ns, not significant. 
plates in the presence or absence of TGF $\beta 1$ and/or inhibitors. After 6-7 days cells were fixed in 4\% PFA for $20 \mathrm{~min}$. Slides were blocked for $1 \mathrm{~h}$ at room temperature using Roche blocking reagent (0.5\% Blocking Solution; Roche Applied Science). Primary antibodies against rabbit anti-NR2E3 (1:50; Millipore), rabbit anti-recoverin (1: 250; Millipore) were diluted in blocking reagent and incubated overnight at $4^{\circ} \mathrm{C}$. Primary antibody labeling was detected using donkey anti-rabbit or anti-mouse antibodies labeled with AlexaFluor 488 (1:500, Molecular Probes; Invitrogen) for $2 \mathrm{~h}$ at room temperature. DAPI was used to counterstain the cell nuclei, and slides were mounted with VECTASHIELD (VECTASHIELD; Vector Laboratories). Fluorescent images were captured with identical exposure times using a Zeiss LSM710 confocal microscope and identically processed using Carl Zeiss Zen imaging software (Carl Zeiss Microscopy GmbH).

\section{Statistical analysis}

For PCR and western blots, the integrated optical density of each band was calculated using ImageJ software (ImageJ v3.9u; NIH). The optical density of each band was normalized by dividing the optical density of the sample by the optical density of its corresponding control gene ( $\beta$-actin) band. Histograms were generated to represent the pixel intensities of each band. For ELISA, a standard curve was plotted of diluted standard solutions for each experiments (DKK1, WNT2B, and WNT5B) using Curve Expert 1.3 software. The concentration of proteins in each of the samples was identified by extrapolation to the generated curve. Statistical analysis of all results was carried out using Graphpad Prism 5 software. Statistical differences were calculated using paired Student's $t$-test or oneway repeated measures ANOVA. The standard error of the mean was plotted as error bars on bar charts and a probability of $<0.05$ was considered to be significant.

\section{Results}

TGF $\beta 1$ modulates the expression of components of the canonical and noncanonical Wnt signaling pathway in $\mathrm{hMSC}$

TGF $\beta$ signaling through smad $2 / 3$ has been demonstrated to regulate photoreceptor regeneration in the adult zebrafish [10], while the canonical Wnt signaling pathway has been shown to regulate proliferation and differentiation of Müller glia-derived progenitors $[22,23]$. On this basis we first investigated whether hMSC expressed molecular components of the Wnt signaling pathway, and whether TGF $\beta$, which is upregulated during retinal gliosis [24], had any effect on the expression of these molecules. RT-PCR analysis showed that hMSC express mRNA coding for WNT2B, WNT3A, WNT5B, WNT11, FZD1, FZD4, FZD7, and $\beta$-CATENIN under baseline conditions. Transcripts for WNT8B and FZD5 were not detected despite the use of three different primers and variations in assay parameters (Fig. 1A). Three different hMSC cell lines named, MIO-M8, MIO-M7, and MIO-M1, when cultured with various concentrations of TGF $\beta 1$ for 7 days showed that mRNA expression coding for the $W N T 2 B$ ligand consistently decreased in a doseresponse manner (Fig. 1B). As compared with the controls, concentrations as low as $0.1 \mathrm{ng} / \mathrm{mL}$ reached significant differences in all the three cell lines. Increasing $\log _{10}$ con- centrations between 1 and $100 \mathrm{ng} / \mathrm{mL}$ of TGF $\beta 1$ induced a further decrease $(P<0.001$ for all the cell lines examined) in the expression of this gene, without showing significant differences among them (Fig. 1B). Corresponding to that seen with mRNA expression, western blot analysis of MIOM1 cells cultured with $50 \mathrm{ng} / \mathrm{mL}$ of TGF $\beta 1$ showed a significant decrease $(P<0.05)$ in intracellular WNT2B protein levels as compared with cells cultured in medium alone. Interestingly, the levels of WN2B ligand present in culture supernatants were minimally detected in both control and TGF $\beta 1$-treated cells (below $1 \mathrm{pg} / \mathrm{mL}$ ) and there were no differences between the two conditions (Fig. 1C).

In contrast to the downregulation of WNT2B mRNA caused by TGF $\beta 1$ in hMSC, mRNA expression of the $W N T 5 B$ ligand was consistently increased by TGF $\beta 1$ in a dose-response manner (Fig. 2A). Although concentrations
A
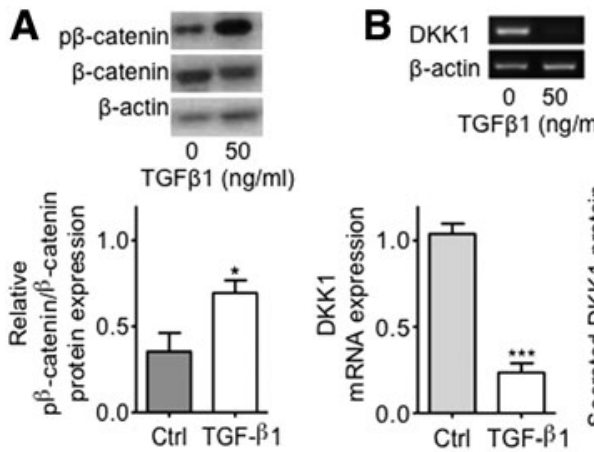

TGFß1 (ng/ml)
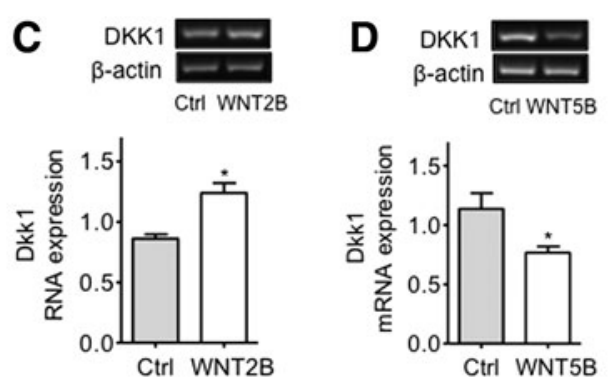

FIG. 3. Modulation of $\mathrm{p} \beta$-catenin and DKK1 protein expressions by TGF $\beta 1$ and effect of exogenous WNT2B and WNT5B ligands on DKK1 mRNA expression. (A) Western blot analysis revealed that culture of hMSC with $50 \mathrm{ng} / \mathrm{mL}$ of TGF $\beta 1$ induced a significant upregulation of the ratio of phospho- $\beta$-catenin/ $\beta$-catenin. Histograms represent the mean \pm SEM of the relative optical density readings of gel bands. Representative bands are shown above the histograms; $n=5$. Student's $t$-test, ${ }^{*} P<0.05$. $\quad \mathrm{p} \beta$-catenin $=$ phospho- $\beta$ catenin. (B) TGF $\beta 1$ caused a significant decrease in DKK1 mRNA expression in hMSC as revealed by RT-PCR analysis. Histograms represent the mean \pm SEM from UV spectrophotometer readings of gel bands. Representative bands are shown above the histograms; $n=8$. Student's $t$-test; $* * * P<0.001$. Secreted DKK1 protein levels as determined by ELISA methods were significantly decreased in culture supernatants of cells treated with $50 \mathrm{ng} / \mathrm{mL}$ of TGF $\beta 1$ as compared to controls; $n=4$. Student's $t$-test; $* P<0.05$. (C) Exogenous addition of recombinant WNT2B into the culture medium induced a significant upregulation of DKK1 mRNA in hMSC; $n=4$. Student's $t$-test, $* P<0.05$. (D) Addition of recombinant WNT5B to cells in culture caused a significant downregulation of $D K K 1 \mathrm{mRNA}$ expression; $n=4$. Student's $t$-test, $* P<0.05$. RT-PCR, reverse transcription-polymerase chain reaction. 
of $0.1 \mathrm{ng} / \mathrm{mL}$ of TGF $\beta 1$ did not cause significant changes in gene expression, increasing $\log _{10}$ concentrations ranging between 1 and $100 \mathrm{ng} / \mathrm{mL}$ of TGF $\beta 1$ induced a significant increase in the expression of WNT5B mRNA $(P<0.05$ for MIO-M8; $P<0.001$ for MIO-M7 and MIO-M1). In agreement with the mRNA findings, culture of hMSC with TGF $\beta 1$ caused a significant increase $(P<0.05)$ in the intracellular levels of WNT5B protein as compared with cells cultured in medium alone (Fig. 2B). Similarly to that seen with the levels of secreted WNT2B in the culture supernatant, secreted WNT5B protein was minimally detected in both control and TGF $\beta 1$-treated cells and there were no difference between the two conditions (Fig. 2C).

Examination of the ratio of phosphorylated $\beta$-catenin over $\beta$-catenin protein expressions showed that the levels of phosphorylated $\beta$-catenin (which indicates that $\beta$-catenin is targeted for degradation) were increased by TGF $\beta 1$ in hMSC $(P<0.05)$ (Fig. 3A). Furthermore, TGF $\beta 1$ caused a significant decrease in the expression of mRNA coding for the canonical Wnt-signaling target $D K K 1(P<0.001)$ and secreted DKK1 protein $(P<0.05)$ compared to cells cultured with medium alone (Fig. 3B). To test the effect of the WNT2B and
WNT5B ligands on Wnt signaling in these cells, we cultured hMSC in the presence or absence of these two ligands and observed that while recombinant WNT2B significantly increased the levels of $D K K 1$ mRNA $(P<0.05)$ (Fig. 3C), recombinant WNT5B markedly decreased the mRNA levels of this target gene in hMSC $(P<0.05)$ (Fig. 3D).

These findings indicate that different adult hMSC lines express various components of the Wnt signaling pathway and that TGF $\beta 1$ downregulates the canonical Wnt signaling ligand WNT2B as well as the active form of $\beta$-catenin, which are important for canonical Wnt signaling. Furthermore, upregulation of the noncanonical Wnt ligand WNT5B by TGF $\beta 1$ may indicate the potential of this cytokine to inhibit the canonical Wnt signaling pathway.

\section{Canonical Wnt signaling components are upregulated by factors that induce photoreceptor differentiation of hMSC}

Our recent studies have demonstrated that adult hMSC can be successfully differentiated into photoreceptors upon culture with FGF2, taurine, retinoic acid, and insulin-like
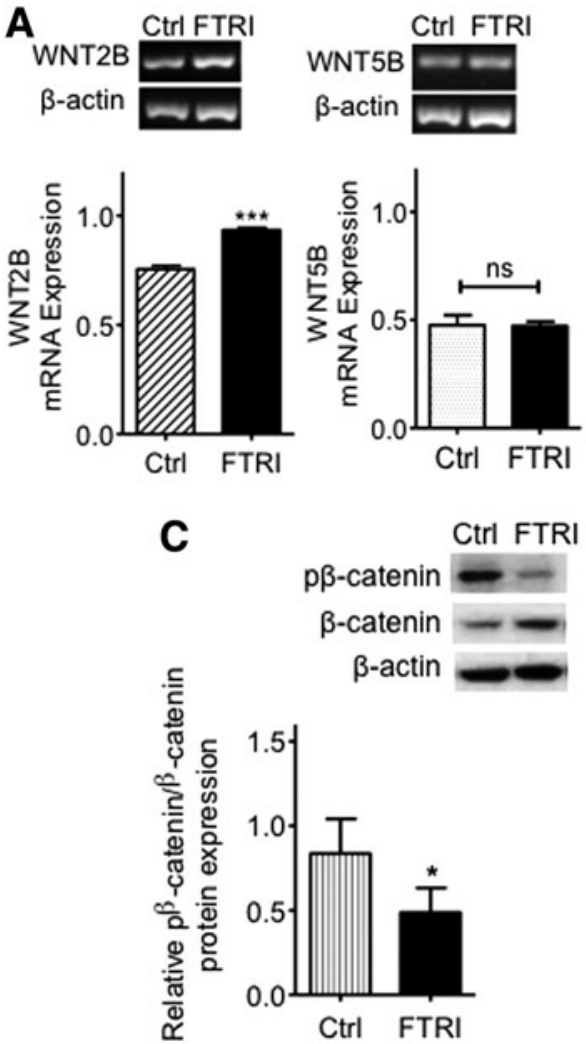

B

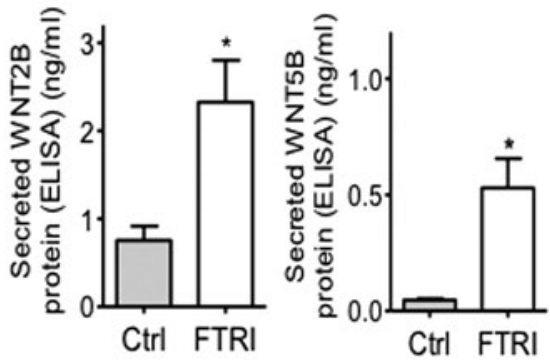

D

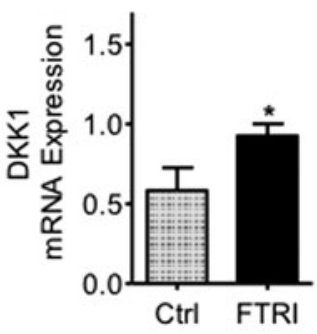

FIG. 4. Induction of photoreceptor differentiation by FTRI causes changes in the expression of the Wnt signaling components WNT2B, $\beta$-catenin, and DKK1 in hMSC. (A) Culture of hMSC with FTRI for 7 days caused a significant increase in the expression of $W N T 2 B$ mRNA, while no changes in the expression of WNT5B were observed in these cells. Histograms represent the mean \pm SEM from UV spectrophotometer readings of gel bands. Representative bands are shown $a b o v e$ the histograms; $n=5$. Student's $t$-test, $* * * P<0.001$. (B) Quantification of the secreted ligands, as measured by ELISA, showed that both WNT2B and WNT5B were significantly increased in culture supernatants of hMSC treated with FTRI for 7 days; $n=3$. Student's $t$-test, $* P<0.05$. (C) Western blotting analysis showed that the ratio of phospho- $\beta$-catenin/ $\beta$-catenin was decreased by FTRI treatment of hMSC. Histograms represent the mean \pm SEM of the relative optical density readings of gel bands. Representative bands are shown above the histograms; $n=5$. Student's $t$-test, $* P<0.05$. $\mathrm{p} \beta$-catenin=phospho- $\beta$-catenin. (D) A significant increase in the expression of $D K K 1 \mathrm{mRNA}$ was observed in hMSC cultured with FTRI for 7 days; $n=3$. Student's $t$-test, $* P<0.05$. ns, not significant; FTRI, FGF2, taurine, retinoic acid and insulin-like growth factor type1. 
growth factor type1 (FTRI) [3]. Given the importance of Wnt signaling in neural stem cell proliferation and differentiation, we examined the effect of FTRI on the Wnt signaling components of hMSC. Interestingly, conditions inducing photoreceptor differentiation of hMSC caused a significant increase in the expression of mRNA coding for the canonical Wnt signaling ligand $W N T 2 B(P<0.001)$, but did not modify the mRNA expression of $W N T 5 B(P=0.46)$ (Fig. 4A). A significant increase in the release of both WNT2B and WNT5B ligands into the culture supernatants was however observed when cells were cultured with FTRI $(P<0.05)$ (Fig. 4B). In addition, western blot analysis demonstrated that the ratio of phospho- $\beta$-catenin/ $\beta$-catenin was significantly decreased in cells undergoing photoreceptor differentiation as compared to undifferentiated hMSC $(P<0.05)$ (Fig. 4C). Furthermore, when culturing cells under photoreceptor differentiating conditions, we also observed an increase in mRNA expression coding for the Wnt target $D K K 1(P<0.05)$ (Fig. 4D).

These observations suggest that opposite to that seen with TGF $\beta 1$ alone, photoreceptor differentiation of hMSC induced by FTRI caused upregulation of the canonical Wnt signaling pathway in hMSC. This suggests that FTRI promotes signaling in hMSC through the Wnt canonical pathway.

\section{TGF $\beta 1$ inhibition of photoreceptor differentiation is associated with changes in the expression of Wnt ligands}

Having shown that photoreceptor differentiation of hMSC promotes activation of the canonical Wnt signaling pathway
A
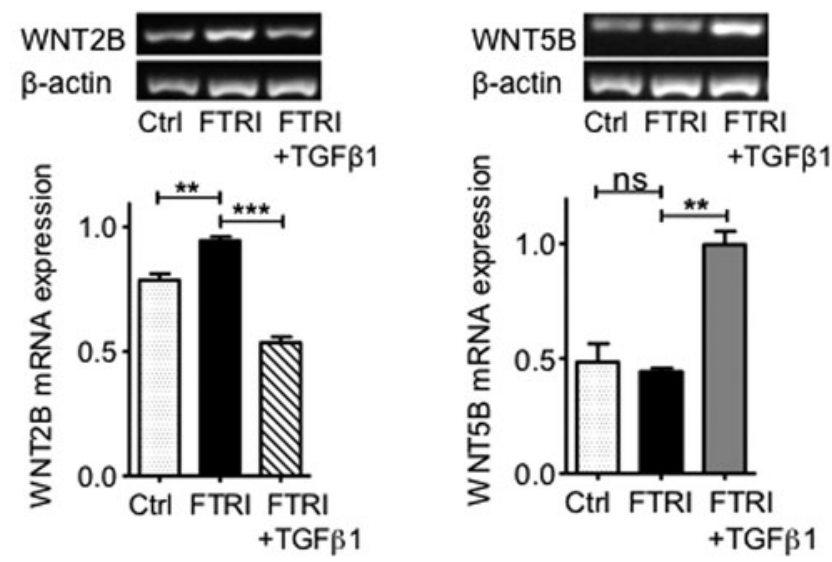

B
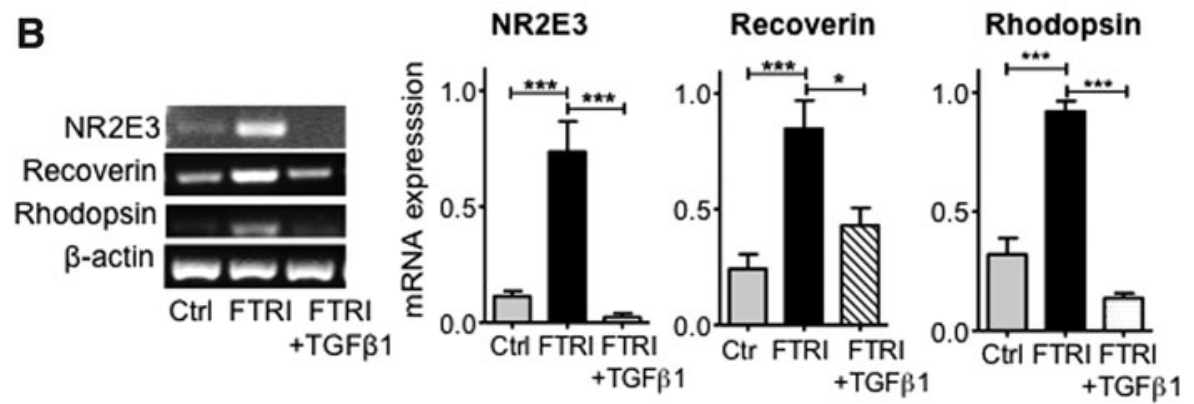

C
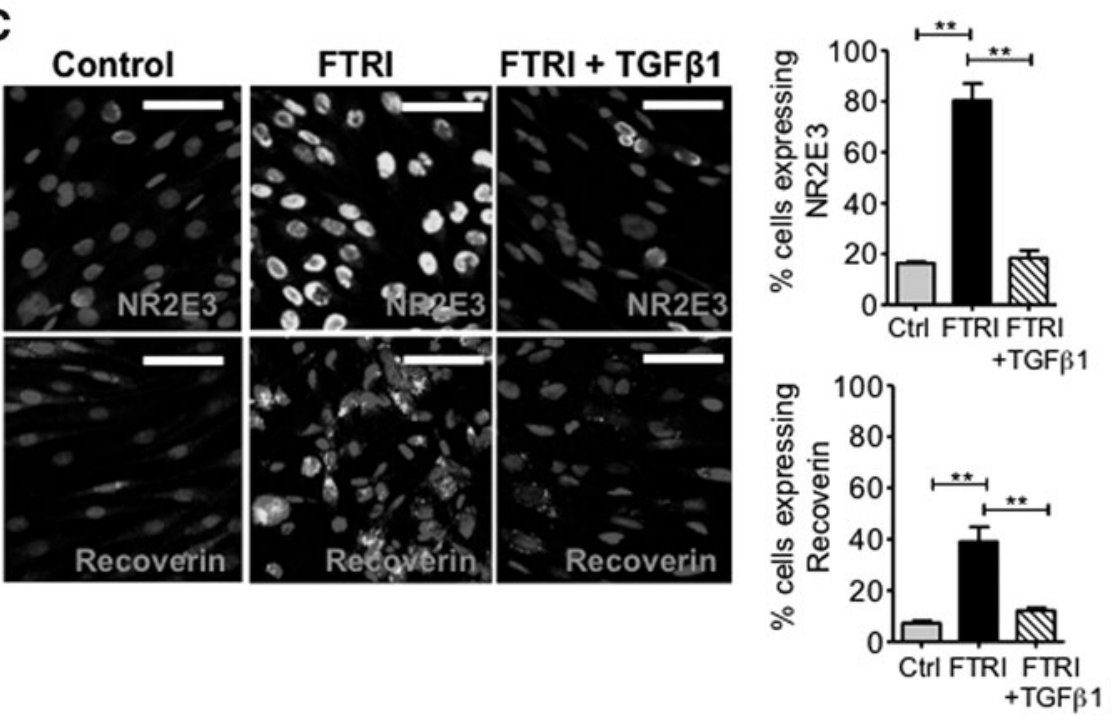

FIG. 5. Inhibition of FTRIinduced photoreceptor differentiation of hMSC by TGF $\beta 1$. (A) Culture of MIO-M1 cells with FTRI caused an increase in $W N T 2 B$ mRNA expression, but addition of TGF $\beta 1$ to the differentiation medium inhibited this increase; $n=4$. ANOVA test, $* * P<0.01 ; \quad * * * P<0.001$. FTRI alone did not modify WNT5B mRNA expression, but addition of TGF $\beta 1$ to the differentiation cocktail increased WNT5B mRNA expression (similar to that shown above with TGF $\beta 1$ alone). Histograms represent the mean \pm SEM from UV spectrophotometer readings of gel bands. Representative bands are shown above the histograms; $n=3$. ANOVA test, $* * P<0.01$; *** $P<0.001$. (B) Addition of TGF $\beta 1$ to hMSC undergoing photoreceptor differentiation with FTRI inhibited the mRNA expression of $N R 2 E 3$, recoverin, and rhodopsin as compared with FTRI alone; $n=5-8$. ANOVA test, $* P<0.05$; $* * * P<0.001$. (C) Immunostaining for NR2E3 and recoverin confirmed that while FTRI alone caused a marked increase in the expression of this photoreceptor protein, addition of TGF $\beta 1$ to hMSC cultured with FTRI caused inhibition of photoreceptor differentiation (Alexa 488, fluorescent cells). Cell nuclei counterstained with DAPI (non-fluorescent cell structures). Scale bars $50 \mu \mathrm{m}$. Histograms on the right represent the proportion of cells immunostaining for each of the markers following 7-day culture under the different conditions; $n=3$. ANOVA test, $* * P<0.01$. 
and that TGF $\beta 1$ downregulates canonical Wnt signaling components while upregulating the noncanonical WNT5B ligand (Figs. 1 and 2), we examined whether TGF $\beta 1$ can modulate photoreceptor differentiation of hMSC by modifying the Wnt signaling pathway in these cells.

Addition of TGF $\beta 1$ to hMSC cultured in the presence of FTRI caused a significant decrease $(P<0.001)$ in $W N T 2 B$ mRNA expression, as compared to hMSC cultured with FTRI alone (Fig. 5A). Cells cultured under differentiating conditions in the presence of TGF $\beta 1$ also showed a significant increase in WNT5B mRNA expression $(P<0.01)$ as compared to cells cultured in the presence of FTRI alone (Fig. 5A). These results suggest that by modifying the expression of the Wnt ligands WNT2B and WNT5B, TGF $\beta 1$ inhibits the effect of FTRI on hMSC. To assess whether this inhibitory effect was reflected on the ability of these cells to differentiate into photoreceptors, TGF $\beta 1$ was added to hMSC cultured with FTRI. Under photoreceptor differentiating conditions, TGF $\beta 1$ caused a significant downregulation of mRNA coding for the photoreceptor markers NR2E3 $(P<0.001)$, RECOVERIN $(P<0.05)$, and RHODOPSIN $(P<0.001)$ as compared to hMSC cultured with FTRI alone (Fig. 5B). This was confirmed by a decrease in the number of cells expressing NR2E3 $(P<0.01)$ and RECOVERIN $(P<0.01)$ when cells were cultured with FTRI in the presence of TGF $\beta 1$, as compared to cells cultured with FTRI alone (Fig. 5C).

To assess whether inhibition of TGF $\beta$ signaling may modify the effect of this cytokine on the expression of $W N T 2 B$ and $W N T 5 B$, we inhibited components of the TGF $\beta$ signaling pathway using the ALK5 receptor inhibitor SB431542 and the JNK inhibitor SP600125. As previously observed, Figure $6 \mathrm{~A}$ shows that TGF $\beta 1$ alone caused a significant decrease in the expression of the WNT2B mRNA as compared with control cells $(P<0.01)$. However, addition of SB431542 markedly inhibited this effect $(P<0.05)$ (Fig. $6 \mathrm{~A})$. Unlike that seen with the ALK5 inhibitor, addition of the JNK inhibitor SP600125 did not cause any effect on the downregulation of $W N T 2 B$ mRNA by TGF $\beta 1 \quad(P=0.91)$ (Fig. 6A). This suggests that mRNA downregulation of the Wnt signaling ligand $W N T 2 B$ by TGF $\beta 1$ is caused by activation of the SMAD2/3 signaling cascade. Similarly, the increase in $W N T 5 B$ expression induced by TGF $\beta 1$ alone $(P<0.01)$ was inhibited by addition of SB431542 $(P<0.01)$ (Fig. 6B). This contrasts with the lack of inhibitory effect by JNK (SP600125) inhibitors $(P=0.14)$ (Fig. 6B). These observations suggest that the TGF $\beta 1$-induced upregulation of $W N T 5 B$ expression in hMSC is also dependent of SMAD2/3 signaling, but independent of JNK transcription signaling. Taken together, these results suggest that TGF $\beta 1$ may regulate hMSC photoreceptor differentiation by modifying the ligands WNT2B and WNT5B of the Wnt signaling pathway.

\section{The canonical Wnt signaling is required for photoreceptor differentiation of hMSC}

Following observations that FTRI, which induces photoreceptor differentiation of hMSC, causes upregulation of canonical Wnt signaling components in these cells, we examined whether Wnt signaling is required for hMSC photoreceptor differentiation. We first tested the effect of the tankyrase inhibitor XAV-939, known to effectively block $\beta$ catenin by stabilizing axin [25], on undifferentiated cells,
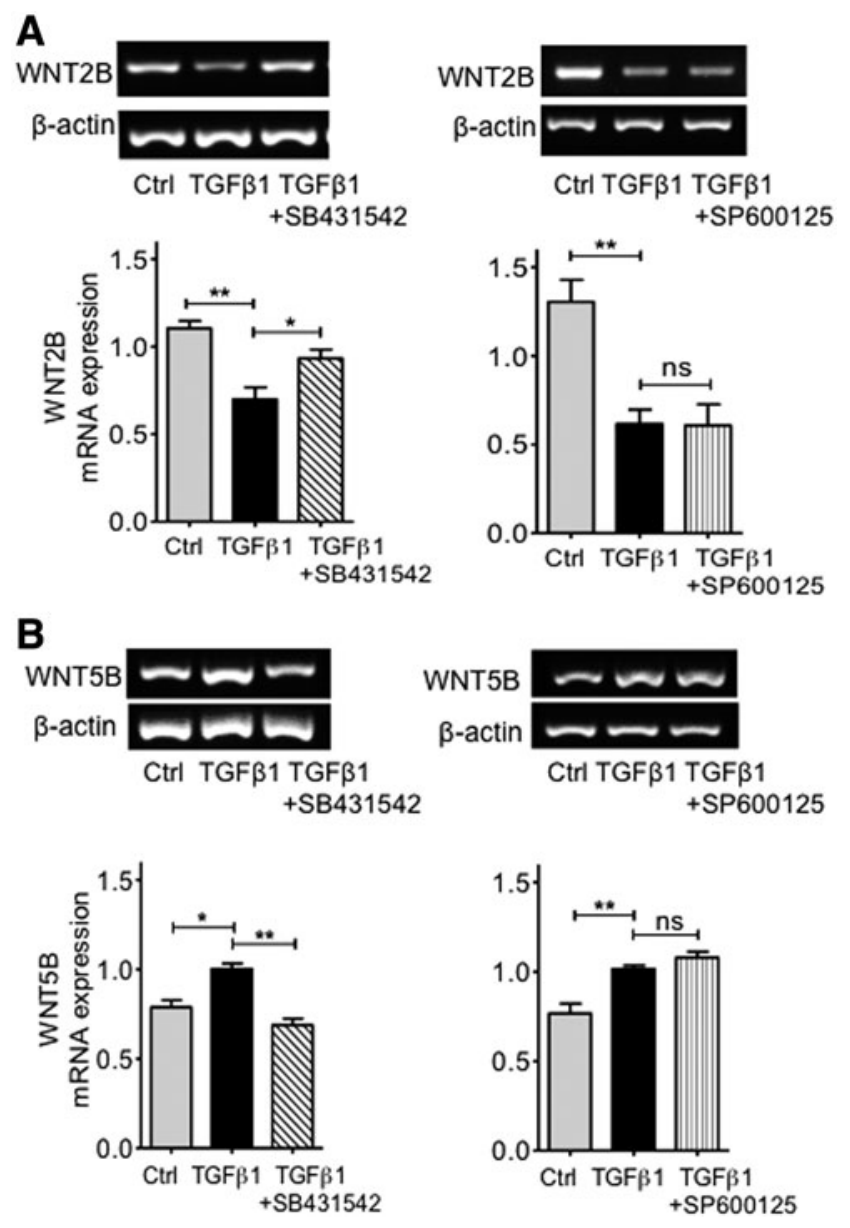

FIG. 6. Effect of TGF $\beta 1$ inhibitors on the expression of the Wnt signaling ligands WNT2B and WNT5B by hMSC. (A) Addition of the TGF $\beta$ type I receptor (ALK5) inhibitor SB431542 $(10 \mu \mathrm{M})$ to cells cultured with TGF $\beta 1$ antagonized the inhibitory effects of this cytokine on $W N T 2 B$ mRNA expression; $n=5$. ANOVA test; $* P<0.05$; $* * P<0.01$. In contrast, addition of the JNK inhibitor SP600125 $(20 \mu \mathrm{M})$ to cells cultured in the presence of TGF $\beta 1$ did not modify the effect of this cytokine on $W N T 2 B$ gene expression. Histograms represent the mean \pm SEM from UV spectrophotometer readings of gel bands. Representative bands are shown above the histograms; $n=3$. ANOVA test, $* * P<0.01$. (B) While the ALK5 inhibitor SB431542 antagonized the upregulation of $W N T 5 B$ mRNA by TGF $\beta 1 ; n=3$. ANOVA test; $* P<0.05$; $* * P<0.01$, the JNK inhibitor SP600125 did not modify the effects of this cytokine on the expression of this ligand gene; $n=4$. ANOVA test, $* * P<0.01$; ns, not significant.

and observed that increasing $\log _{10}$ concentrations of this compound caused a gradual increase in the expression of phosphorylated $\beta$-catenin. Although significant increase was only observed with concentrations above $10 \mathrm{nM}(P<0.05)$ (Fig. 7A). Addition of XAV-939 (10 nM) to hMSC cultured under photoreceptor differentiating conditions caused a significant inhibition of the effect of FTRI on the mRNA expression of the photoreceptor markers NR2E3 $(P<0.01)$ and RECOVERIN $(P<0.05)$ (Fig. 7B). This inhibition was further confirmed by immunocytochemical analysis, which also demonstrated a significant decrease in the number of cells expressing NR2E3 $(P<0.01)$ and RECOVERIN 
A

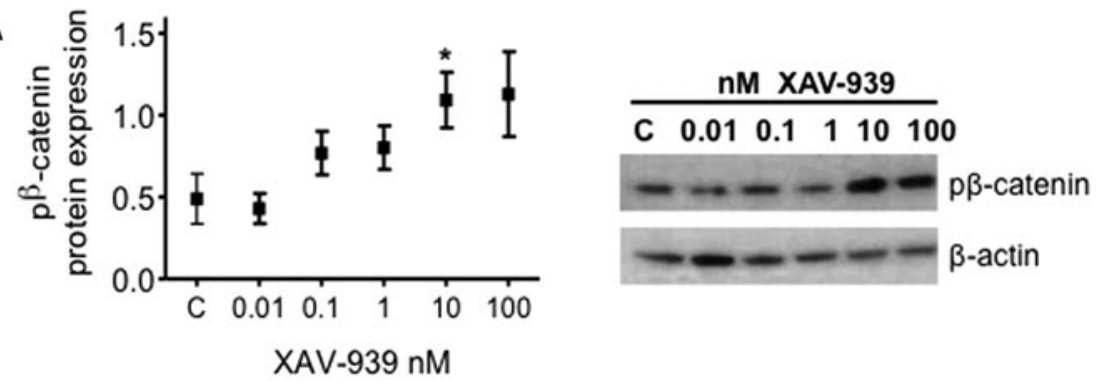

B
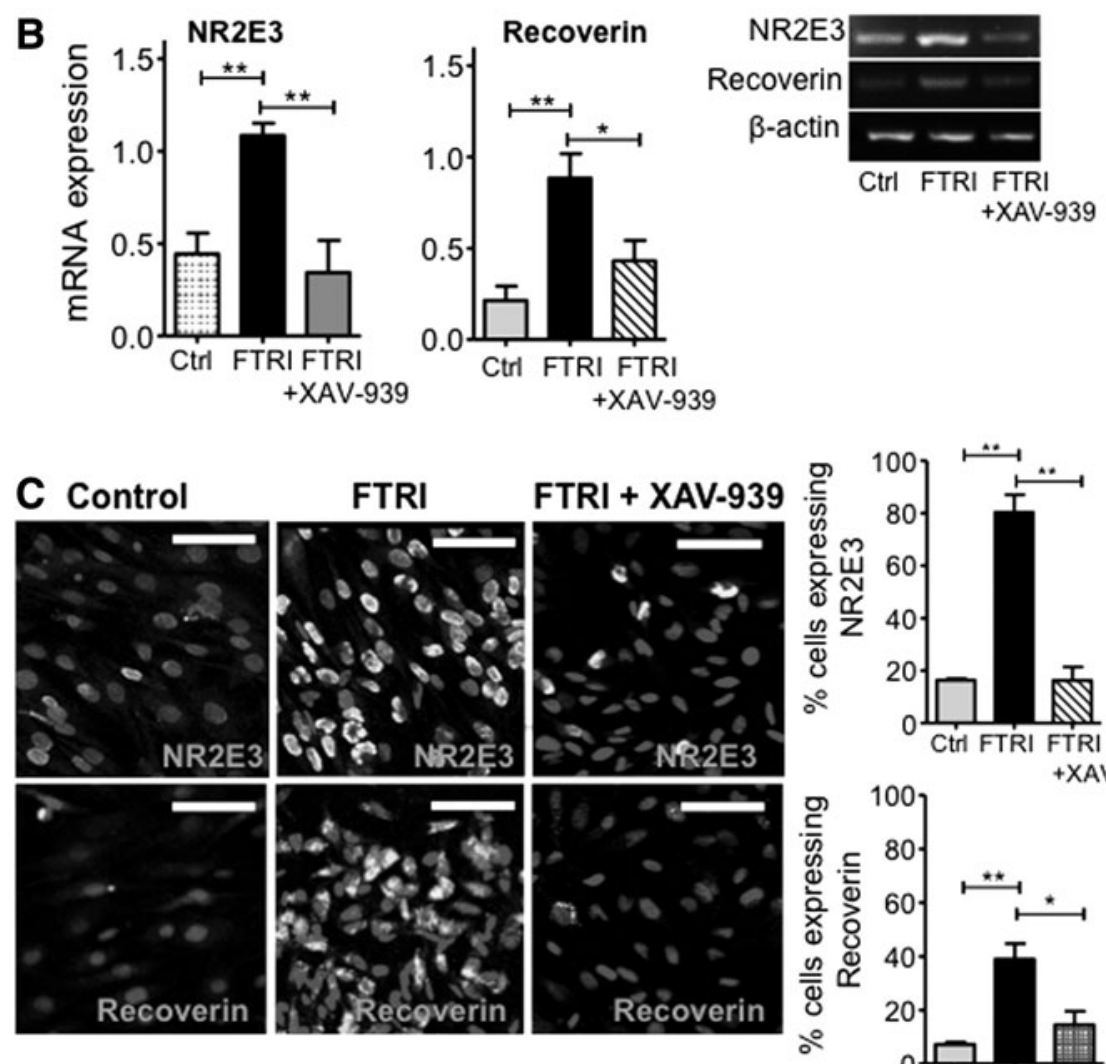

$(P<0.05)$ proteins in hMSC cultured with FTRI in the presence of XAV-939 $(P<0.01)$ (Fig. 7C). Taken together, these results suggest that signaling through the canonical Wnt pathway precedes the activation of proneural factors involved in the differentiation of hMSC into photoreceptors.

\section{Discussion}

Müller glia, which are responsible for the spontaneous retina regeneration observed in zebrafish [10,26], have also shown limited regenerative ability in early postnatal life in small vertebrates $[27,28]$. Although a population of Müller glia isolated from the adult human retina exhibit stem cell characteristics in vitro [2], there is no indication that these cells have any regenerative ability in vivo. There is much evidence for the roles of TGF $\beta$ and Wnt signaling in the mediation of cellular processes regulating Müller glia differentiation in the zebrafish retina [10,29], and rodent retina [30], as well as in the patterning of the eye during embry-
FIG. 7. Effect of inhibition of $\beta$ CATENIN on the photoreceptor differentiation of hMSC. (A) Doseresponse increase in $\mathrm{p} \beta$-CATENIN expression by hMSC cultured with concentrations of XAV939 ranging between 0.01 and $100 \mathrm{nM}$. Western blot bands on the right show that XAV-939 significantly upregulated the expression of $\mathrm{p} \beta$-CATENIN protein at concentrations of 10 and $100 \mathrm{nM} ; n=4$. Student's $t$-test, $* P<0.05$. $\quad \mathrm{p} \beta$-catenin $=$ phospho- $\beta$ catenin. (B) Addition of XAV-939 to hMSC cultured with FTRI inhibited the differentiation of these cells into photoreceptors, as judged by the expression of mRNA coding for NR2E3 and RECOVERIN. Histograms on the left represent the mean \pm SEM from UV spectrophotometer readings of gel bands. Representative bands are shown on right of the histograms; $n=5-7$. ANOVA test; $* P<0.05 ; \quad * * P<$ 0.01. (C) Confocal images confirmed that addition of XAV-939 to hMSC cultured in the presence of FTRI caused a decrease in the expressions of NR2E3 and recoverin, which is upregulated by FTRI alone (Alexa 488, fluorescent cells). Cell nuclei counterstained with DAPI (non-fluorescent cell structures). Scale bars $50 \mu \mathrm{m}$. Histogram represents the percentage of cells stained with NR2E3 following 7 days culture under the different conditions; $n=3$. ANOVA test; $* P<0.05 ; * * P<0.01$. onic development [31,32]. However, very little is known of the role of these factors in the regulation of progenicity and neural differentiation of Müller glia in the adult human eye.

Activation of the TGF $\beta$ and Wnt signaling pathways require the expression of specific receptors on the cell surface, and as previously shown, mammalian Müller glia express TGF $\beta$ and Wnt receptors and their ligands [19,33-35], for which it is possible that activation of these pathways may trigger the neurogenic properties of human Müller glia as observed in other species. As illustrated in Figure 8, our results showed that TGF $\beta$ caused in vitro downregulation of the canonical Wnt signaling pathway in hMSC. This was demonstrated by a decrease in the expression of WNT2B, DKK1, and active $\beta$-CATENIN in cells cultured with this cytokine. In contrast, FTRI, which induces photoreceptor differentiation of hMSC [3], upregulated the expression of genes and proteins associated with the canonical Wnt signaling pathway. More important, addition of TGF $\beta 1$ to hMSC cultured with FTRI resulted in inhibition of the 


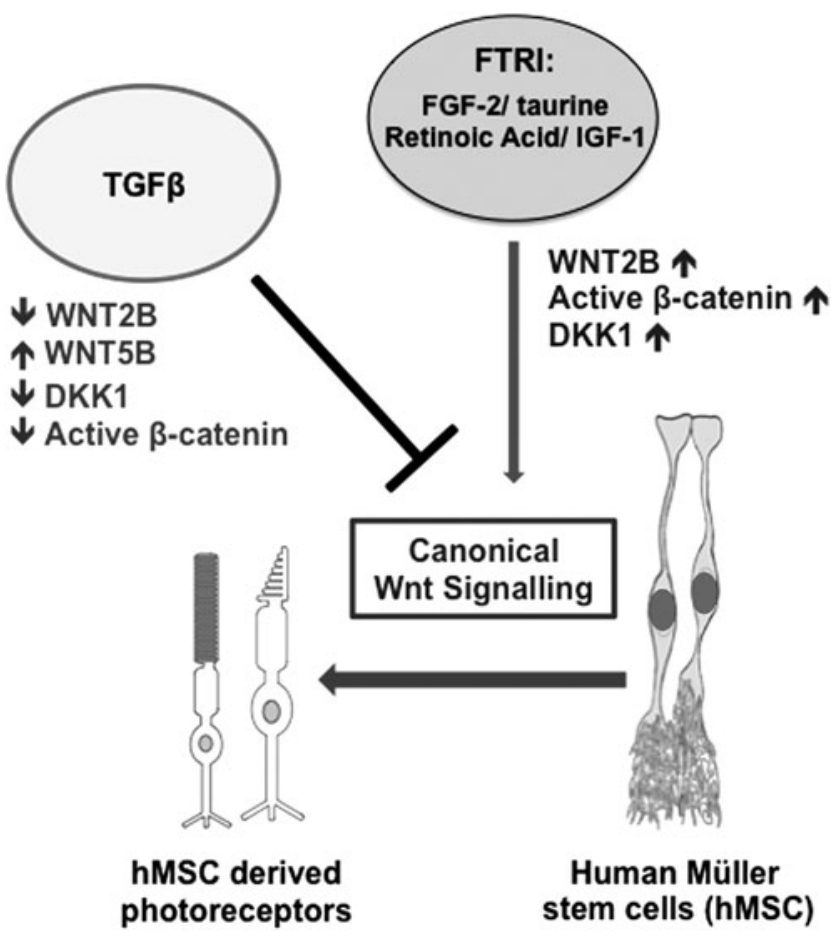

FIG. 8. TGF $\beta 1$ inhibits the canonical Wnt signaling pathway necessary for the photoreceptor differentiation of hMSC in vitro. Schematic illustration summarizing the interactions of FTRI, WNT2B, WNT5B, TGF 1 , and DKK1 in hMSC. FTRI, which induces photoreceptor differentiation of hMSC, activated the canonical Wnt signaling pathway in these cells. Addition of TGF $\beta 1$ to cells cultured with FTRI caused inhibition of the canonical Wnt signaling and consequently inhibited the photoreceptor differentiation of hMSC in vitro.

photoreceptor differentiation. These findings suggest that as seen in the zebrafish and early postnatal life in small vertebrates, photoreceptor differentiation of hMSC requires activation of canonical Wnt signaling and that by modulating this pathway, TGF $\beta 1$ may control the neurogenic ability of these cells in the human eye.

It has been documented that loss of TGF $\beta$ or Wnt $5 \mathrm{a}$ (which shares $80 \%$ protein sequence with human WNT5B (www.omim.org/entry/606361) in mouse mammary cells, results in increased $\mathrm{Wnt} / \beta$-catenin activity [36], and that TGF $\beta$ signaling in mouse embryos blocks the canonical Wnt pathway, leading to inhibition of midbrain development [37]. In addition, overexpression of wnt5b in zebrafish causes downregulation of the canonical Wnt target axin2, with consequent inhibition of tail fin regeneration [38]. Therefore, the present findings that inhibition of photoreceptor differentiation by TGF $\beta 1$ in hMSC was accompanied by gene downregulation of $W N T 2 B$ and upregulation of $W N T 5 B$, is in accordance with the reported functions of this ligand in promoting the activation of the canonical Wnt signaling pathway in other species. This suggests that by increasing WNT5B expression, TGF $\beta 1$ may potentiate its inhibitory effect that prevents photoreceptor differentiation of hMSC. That FTRI upregulates the expression of WNT2B strongly suggests that the effect of these factors on the photoreceptor differentiation of hMSC may be exerted through the activation of the canonical Wnt signaling pathway.
Regulation of intracellular functions by TGF $\beta$ involves the activation of SMAD proteins that translocate to the nucleus, where they regulate transcription, as well as SMAD-independent pathways such as those involving JNK and p38 activation [39]. We observed that SB431542, an inhibitor of ALK5 receptor, which selectively blocks the SMAD2/3-dependent pathway [40], antagonized the effect of this cytokine on the downregulation of WNT2B. Similarly, upregulation of WNT5B was antagonized by the ALK5 receptor inhibitor SB431542. This contrasted with the lack of effect of the JNK inhibitor on the modulation of both ligands by TGF $\beta 1$. These results suggest that modulation of the expression of WNT2B and WNT5B by TGF $\beta 1$ might be caused by SMAD signaling activation. Previous studies have shown that in the zebrafish regulation of Smad2/3 signaling in Müller glia is important for the proliferative and neurogenic response of these cells to retinal damage [10]. Hence, the present observations that known intracellular pathways of Müller cell differentiation observed in zebrafish are also active in human Müller glia in vitro suggest the existence of inhibitory mechanisms of these pathways in the adult human retina, which may prevent these cells from regenerating the retina in vivo. It also raises the prospects that if we can control these mechanisms in hMSC in vitro, we could potentially induce Müller glia to regenerate the retina in vivo.

Involvement of the canonical Wnt signaling pathway in the photoreceptor differentiation of hMSC in vitro is further supported by the present findings that inhibition of Wnt signaling by XAV-939 (which stabilizes axin and consequently targets $\beta$-CATENIN for degradation) in cells cultured with FTRI, prevented photoreceptor differentiation of these cells. Activation of canonical Wnt signaling is associated with the maintenance and proliferation of retinal progenitors in the embryonic chick and mouse retina [41], while laser injury in transgenic mice lacking the Wnt signaling regulator Axin2, induces amplification of Wnt signaling and generation of rhodopsin-positive cells from Müller glia [35]. Wnt signaling activation is also associated with Müller glia-mediated regeneration in the zebrafish [20], and continuous activation of this pathway after acute injury in larval zebrafish also promotes the generation of neuronal progenitors from Müller glia [29].

To summarize, we have demonstrated that differentiation of hMSC into photoreceptors in vitro is dependent on the activation of the canonical Wnt signaling pathway and that TGF $\beta$, which is highly upregulated during gliosis [24], modifies Wnt signaling mechanisms in hMSC (Fig. 8). That hMSC express genes of the Wnt signaling pathway and that their activation regulates photoreceptor differentiation upon culture with differentiation factors may reflect their potential regenerative ability in vivo. Given that signaling cascades elicited by binding of TGF $\beta$ and Wnt ligands to their receptors involve cross talks of intracellular signaling pathways [42], it may be possible that regulation of TGF $\beta$ and Wnt signaling may have diversified during evolution to prevent uncontrolled growth and differentiation of human Müller glia in the adult retina. It may be also possible that factors released during inflammation and gliosis could inhibit the regenerative ability of these cells in vivo. On this basis, comparative investigations into mechanisms that control these pathways in zebrafish and human Müller glia 
may help to identify therapeutic targets that could be potentially used to promote endogenous regeneration of the human retina, and this merits further investigations.

\section{Acknowledgments}

This work was supported by the MRC China-UK initiative, MRC grant Ref. MR/K008722/1; National Science Foundation of China, grant Ref. 81261130316; Fight for Sight (through a donation of Mr. T Bickford), the Special Trustees of Moorfields Eye Hospital and the NIHR Biomedical Research Center at Moorfields Eye Hospital, and UCL Institute of Ophthalmology, London. A.A. is a recipient of a UCL Grand Challenges Scholarship.

\section{Author Disclosure Statement}

No competing financial interests exist.

\section{References}

1. Bernardos RL, LK Barthel, JR Meyers and PA Raymond. (2007). Late-stage neuronal progenitors in the retina are radial Müller glia that function as retinal stem cells. J Neurosci 27:7028-7040.

2. Lawrence JM, S Singhal, B Bhatia, DJ Keegan, TA Reh, PJ Luthert, PT Khaw and GA Limb. (2007). MIO-M1 cells and similar Müller glial cell lines derived from adult human retina exhibit neural stem cell characteristics. Stem Cells 25:2033-2043.

3. Jayaram H, MF Jones, K Eastlake, PB Cottrill, S Becker, J Wiseman, PT Khaw and GA Limb. (2014). Transplantation of photoreceptors derived from human Müller glia restore rod function in the P23H rat. Stem Cells Transl Med 3:323-333.

4. Singhal S, B Bhatia, H Jayaram, S Becker, MF Jones, PB Cottrill, PT Khaw, TE Salt and GA Limb. (2012). Human Müller glia with stem cell characteristics differentiate into retinal ganglion cell (RGC) precursors in vitro and partially restore RGC function in vivo following transplantation. Stem Cells Transl Med 1:188-199.

5. Becker S, S Singhal, MF Jones, K Eastlake, PB Cottrill, H Jayaram and GA Limb. (2013). Acquisition of RGC phenotype in human Müller glia with stem cell characteristics is accompanied by upregulation of functional nicotinic acetylcholine receptors. Mol Vis 19:1925-1936.

6. Bringmann A, I Iandiev, T Pannicke, A Wurm, M Hollborn, P Wiedemann, NN Osborne and A Reichenbach. (2009). Cellular signaling and factors involved in Müller cell gliosis: neuroprotective and detrimental effects. Prog Retin Eye Res 28:423-451.

7. Guo C, Z Zhang, P Zhang, J Makita, H Kawada, K Blessing and PF Kador. (2014). Novel transgenic mouse models develop retinal changes associated with early diabetic retinopathy similar to those observed in rats with diabetes mellitus. Exp Eye Res 119:77-87.

8. Wang X, S Abraham, JA McKenzie, N Jeffs, M Swire, VB Tripathi, UF Luhmann, CA Lange, Z Zhai, et al. (2013). LRG1 promotes angiogenesis by modulating endothelial TGF-beta signalling. Nature 499:306-311.

9. Paine SK, A Basu, LK Mondal, A Sen, S Choudhuri, IH Chowdhury, A Saha, G Bhadhuri, A Mukherjee and B Bhattacharya. (2012). Association of vascular endothelial growth factor, transforming growth factor beta, and interferon gamma gene polymorphisms with proliferative dia- betic retinopathy in patients with type 2 diabetes. Mol Vis 18:2749-2757.

10. Lenkowski JR, Z Qin, CJ Sifuentes, R Thummel, CM Soto, CB Moens and PA Raymond. (2013). Retinal regeneration in adult zebrafish requires regulation of TGF signaling. Glia 61:1687-1697.

11. Oshimori $\mathrm{N}$ and $\mathrm{E}$ Fuchs. (2012). The harmonies played by TGF-beta in stem cell biology. Cell Stem Cell 11:751-764.

12. Nishita M, MK Hashimoto, S Ogata, MN Laurent, N Ueno, H Shibuya and KW Cho. (2000). Interaction between Wnt and TGF-beta signalling pathways during formation of Spemann's organizer. Nature 403:781-785.

13. Satterwhite DJ and KL Neufeld. (2004). TGF-beta targets the Wnt pathway components, APC and beta-catenin, as Mv1Lu cells undergo cell cycle arrest. Cell Cycle 3:10691073.

14. Tuli R, S Tuli, S Nandi, X Huang, PA Manner, WJ Hozack, KG Danielson, DJ Hall and RS Tuan. (2003). Transforming growth factor-beta-mediated chondrogenesis of human mesenchymal progenitor cells involves $\mathrm{N}$-cadherin and mitogen-activated protein kinase and Wnt signaling crosstalk. J Biol Chem 278:41227-41236.

15. Lie DC, SA Colamarino, HJ Song, L Desire, H Mira, A Consiglio, ES Lein, S Jessberger, H Lansford, AR Dearie and FH Gage. (2005). Wnt signalling regulates adult hippocampal neurogenesis. Nature 437:1370-1375.

16. van Amerongen R, A Mikels and R Nusse. (2008). Alternative wnt signaling is initiated by distinct receptors. Sci Signal 1:re9.

17. Akhmetshina A, K Palumbo, C Dees, C Bergmann, $\mathrm{P}$ Venalis, P Zerr, A Horn, T Kireva, C Beyer, et al. (2012). Activation of canonical Wnt signalling is required for TGFbeta-mediated fibrosis. Nat Commun 3:735.

18. Zhou S. (2011). TGF-beta regulates beta-catenin signaling and osteoblast differentiation in human mesenchymal stem cells. J Cell Biochem 112:1651-1660.

19. Yi H, REI Nakamura, O Mohamed, D Dufort and AS Hackam. (2007). Characterization of wnt signaling during photoreceptor degeneration. Invest Ophthalmol Vis Sci 48:5733-5741.

20. Lenkowski JR and PA Raymond. (2014). Müller glia: stem cells for generation and regeneration of retinal neurons in teleost fish. Prog Retin Eye Res 40:94-123.

21. Bhatia B, S Singhal, JM Lawrence, PT Khaw and GA Limb. (2009). Distribution of Müller stem cells within the neural retina: evidence for the existence of a ciliary margin-like zone in the adult human eye. Exp Eye Res 89:373-382.

22. Del Debbio CB, S Balasubramanian, S Parameswaran, A Chaudhuri, F Qiu and I Ahmad. (2010). Notch and Wnt signaling mediated rod photoreceptor regeneration by Müller cells in adult mammalian retina. PLoS One 5:15.

23. Wan J, R Ramachandran and D Goldman. (2012). HB-EGF is necessary and sufficient for Müller glia dedifferentiation and retina regeneration. Dev Cell 22:334-347.

24. Hoerster R, PS Muether, S Vierkotten, MM Hermann, B Kirchhof and S Fauser. (2014). Upregulation of TGF-1 in experimental proliferative vitreoretinopathy is accompanied by epithelial to mesenchymal transition. Graefes Arch Clin Exp Ophthalmol 252:11-16.

25. Huang S-MA, YM Mishina, S Liu, A Cheung, F Stegmeier, GA Michaud, O Charlat, E Wiellette, Y Zhang, et al. (2009). Tankyrase inhibition stabilizes axin and antagonizes Wnt signalling. Nature 461:614-620. 
26. Ramachandran R, BV Fausett and D Goldman. (2010). Asclla regulates Müller glia dedifferentiation and retinal regeneration through a Lin-28-dependent, let-7 microRNA signalling pathway. Nat Cell Biol 12:1101-U106.

27. Osakada F, S Ooto, T Akagi, M Mandai, A Akaike and M Takahashi. (2007). Wnt signaling promotes regeneration in the retina of adult mammals. J Neurosci 27:4210-4219.

28. Fischer AJ and R Bongini. (2010). Turning Müller glia into neural progenitors in the retina. Mol Neurobiol 42:199-209.

29. Meyers JR, L Hu, A Moses, K Kaboli, A Papandrea and PA Raymond. (2012). $\beta$-Catenin/Wnt signaling controls progenitor fate in the developing and regenerating zebrafish retina. Neural Dev 7:30.

30. Close JL, B Gumuscu and TA Reh. (2005). Retinal neurons regulate proliferation of postnatal progenitors and Müller glia in the rat retina via TGF beta signaling. Development 132:3015-3026.

31. Hagglund A-C, A Berghard and L Carlsson. (2013). Canonical Wnt/beta-Catenin signalling is essential for optic cup formation. PLoS One 8:e81158.

32. Grocott T, S Johnson, AP Bailey and A Streit. (2011). Neural crest cells organize the eye via TGF-beta and canonical Wnt signalling. Nat Commun 2:265.

33. Ikeda T, Y Homma, K Nisida, K Hirase, C Sotozono, S Kinoshita and DG Puro. (1998). Expression of transforming growth factor-beta $s$ and their receptors by human retinal glial cells. Curr Eye Res 17:546-550.

34. Yafai Y, I Iandiev, J Lange, JD Unterlauft, P Wiedemann, A Bringmann, A Reichenbach and W Eichler. (2014). Müller glial cells inhibit proliferation of retinal endothelial cells via TGF-beta 2 and Smad signaling. Glia 62:1476-1485.

35. Liu B, DJ Hunter, S Rooker, A Chan, YM Paulus, P Leucht, Y Nusse, H Nomoto and JA Helms. (2013). Wnt signaling promotes Müller cell proliferation and survival after injury. Invest Ophthalmol Vis Sci 54:444-453.

36. Roarty K, SE Baxley, MR Crowley, AR Frost and R Serra. (2009). Loss of TGF-beta or Wnt5a results in an increase in Wnt/beta-catenin activity and redirects mammary tumour phenotype. Breast Cancer Research 11:R19.
37. Falk S, H Wurdak, LM Ittner, F Ille, G Sumara, M-T Schmid, K Draganova, KS Lang, C Paratore, et al. (2008). Brain area-specific effect of TGF-beta signaling on Wntdependent neural stem cell expansion. Cell Stem Cell 2:472-483.

38. Stoick-Cooper CL, G Weidinger, KJ Riehle, C Hubbert, MB Major, N Fausto and RT Moon. (2007). Distinct Wnt signaling pathways have opposing roles in appendage regeneration. Development 134:479-489.

39. Derynck R and YE Zhang. (2003). Smad-dependent and Smad-independent pathways in TGF-beta family signalling. Nature 425:577-584.

40. Inman GJ, FJ Nicolas, JF Callahan, JD Harling, LM Gaster, AD Reith, NJ Laping and CS Hill. (2002). SB-431542 is a potent and specific inhibitor of transforming growth factorbeta superfamily type I activin receptor-like kinase (ALK) receptors ALK4, ALK5, and ALK7. Mol Pharmacol 62: 65-74.

41. Cho SH and CL Cepko. (2006). Wnt2b/beta-cateninmediated canonical Wnt signaling determines the peripheral fates of the chick eye. Development 133:3167-3177.

42. Xu J, S Lamouille and R Derynck. (2009). TGF-betainduced epithelial to mesenchymal transition. Cell Research 19:156-172.

Address correspondence to: G. Astrid Limb

Division of Ocular Biology and Therapeutics UCL Institute of Ophthalmology 11 Bath Street London EC1V 9EL United Kingdom

E-mail: g.limb@ucl.ac.uk

Received for publication August 14, 2015 Accepted after revision October 9, 2015 Prepublished on Liebert Instant Online October 11, 2015 